\title{
Fast, efficient and reproducible genetic transformation of Phaseolus spp. by Agrobacterium rhizogenes
}

\author{
Georgina Estrada-Navarrete ${ }^{1}$, Xochitl Alvarado-Affantranger ${ }^{1}$, Juan-Elías Olivares ${ }^{1}$, Gabriel Guillén ${ }^{1}$, \\ Claudia Díaz-Camino ${ }^{1}$, Francisco Campos ${ }^{1}$, Carmen Quinto ${ }^{1}$, Peter M Gresshoff ${ }^{2}$ \& Federico Sanchez ${ }^{1}$
}

\begin{abstract}
${ }^{1}$ Departamento de Biología Molecular de Plantas, Instituto de Biotecnología, Universidad Nacional Autónoma de México, Av. Universidad 2001, Colonia Chamilpa, CP 62210, Cuernavaca, Morelos, México. ${ }^{2}$ ARC Centre of Excellence for Integrative Legume Research, The University of Queensland, St. Lucia, Queensland 4072, Australia. Correspondence should be addressed to F.S.R. (federico@ibt.unam.mx).

Published online 19 July 2007; doi:10.1038/nprot.2007.259

This transformation procedure generates, with high efficiency (70-90\%), hairy roots in cultivars, landraces and accessions of Phaseolus vulgaris (common bean) and other Phaseolus spp. Hairy roots rapidly develop after wounding young plantlets with Agrobacterium rhizogenes, at the cotyledon node, and keeping the plants in high-humidity conditions. Callogenesis always precedes hairy-root formation, and after 15 days, when roots develop at wounded sites, the stem with the normal root is cleaved below the hairy root zone. Transgenic roots and nodules co-transformed with a binary vector can be easily identified using a reporter gene. This procedure, in addition to inducing robust transgenic hairy roots that are susceptible to being nodulated by rhizobia and to fixing nitrogen efficiently, sets the foundation for a high-throughput functional genomics approach on the study of root biology and root-microbe interactions. This protocol can be completed within 30 days.
\end{abstract}

\section{INTRODUCTION}

Grain legumes are one of the most valuable sources of dietary proteins for animal and human consumption, and of these, common beans represent $50 \%$ of the grain legume consumed worldwide ${ }^{1}$. In particular, in Latin America and Eastern Africa, it is the primary source of protein in the human $\operatorname{diet}^{2}$. The legumes, such as bean, have the advantage of fixing atmospheric nitrogen through a symbiotic association with nitrogen-fixing soil bacteria. The production of genetically modified common bean plants has been impeded by the availability of efficient techniques for introducing DNA into the plant genome and regeneration methods. A fast, reproducible and efficient transformation procedure is crucial not only for gene function studies, but also to allow crop improvement.

Common bean is reputed to be a species recalcitrant to transformation, limiting the possibilities for the molecular and physiological analysis of gene function. Particle bombardment-mediated systems have been developed to obtain transgenic plants of $P$. vulgaris, but are labor intensive $\mathrm{e}^{3,4}$. Recently, the transformation system based on the bombardment of meristematic tissue of embryonic axes and the use of an efficient selective agent such as imazapyr, an herbicide of the imidazolinone class, was used to obtain transgenic bean plants, resistant to bean geminivirus. Field tests based on RNA interference (RNAi)-mediated resistance to bean golden mosaic virus are currently being evaluated in Brazil ${ }^{5}$.

Bean transformation mediated by Agrobacterium tumefaciens has been unsuccessful previously ${ }^{6}$. However, recent progress has increased the feasibility of transformation as a tool in Phaseolus ${ }^{7}$. Liu et al. ${ }^{8}$ developed a protocol based on the combination of sonication and vacuum infiltration to transform common bean with a late embryogenesis abundant gene, conferring abiotic stress tolerance. As the efficiency is $12 \%$, this method looks very promising, and should be further evaluated. The susceptibility of common and tepary bean cultivars to several A. tumefaciens and A. rhizogenes strains has been previously evaluated ${ }^{9}$. Only one successful report of transformation with A. tumefaciens in a cultivar of Phaseolus acutifolious is available ${ }^{10}$. A. rhizogenes-mediated root transformation has been described for numerous legumes and composite plants with untransformed shoots and transformed roots that can be nodulated by rhizobia and colonized by micorrhiza ${ }^{11}$. Composite plants in legumes provide a fast and convenient alternative transformation procedure to generating stable transgenic lines.

Here, we describe a fast, reproducible and efficient common bean root transformation protocol for different cultivars and landraces of $P$. vulgaris (bean) with $A$. rhizogenes K599. This protocol gives further details of the method used by Estrada-Navarrete et al. ${ }^{12}$. This protocol was also successful for other Phaseolus spp.: $P$. coccineus, $P$. lunatus and $P$. acutifolius ${ }^{11}$. This procedure provides a new tool for functional genomics by enabling the generation of knockdown and gain-of-function composite plants, especially focused on genes involved in root biology and root-microbe interactions.

\section{MATERIALS}

REAGENTS

- $96 \%(\mathrm{v} / \mathrm{v})$ ethanol

-20\% (v/v) commercial bleach CLORALEX (6\% sodium hypochlorite solution)/sterile water $\triangle$ CRITICAL Dilute immediately before the experiment. - Sterile $\mathrm{H}_{2} \mathrm{O}$

- Vermiculite (grade 2 or 3 )
- B\&D solution

-A. rhizogenes K599 (NCPP2659) fresh culture

- Rhizobium tropici strain CIAT899

- Solid LB medium (10 g tryptone, 5 g yeast extract, $10 \mathrm{~g} \mathrm{NaCl}, 15 \mathrm{~g}$ agar per liter)

- Liquid LB medium containing 20\% (v/v) glycerol 
- Liquid PY medium (5 g peptone, 3 g yeast extract per liter)

- $1 \mathrm{M} \mathrm{CaCl}_{2}$ sterile solution

$\cdot 10 \mathrm{mM} \mathrm{MgSO}_{4}$ sterile solution

- $50 \mathrm{mg} \mathrm{ml}^{-1}$ (w/v) rifampicin/dimethylsulfoxide stock solution

$\cdot 20 \mathrm{mg} \mathrm{ml}^{-1}(\mathrm{w} / \mathrm{v})$ nalidixic acid/NaOH $0.1 \mathrm{~N}$ stock solution

- $0.05 \%(\mathrm{v} / \mathrm{v})$ plant preservative mixture (PPM)/sterile $\mathrm{H}_{2} \mathrm{O}$ (Plant Cell

Technology Inc.) ! CAUTION PPM is non-toxic; however, it is recommended

that users wear gloves and splash goggles. Avoid contact with skin and eyes.

Avoid inhalation. Use proper/adequate ventilation. The material should not

be spray-applied except with directed flow, positive pressure ventilation and protective equipment.

- Citifluor (Ted Pella Inc., cat. no. 19470).

EQUIPMENT

- Paper towel

- Aluminum foil

-250 ml Erlenmeyer flasks

- Metallic tray

- Forceps, dressing, $16 \mathrm{~cm}$ (Phytotechnology Lab. cat. no. F950)

- Pots $3.5^{\prime \prime} \times 3.5^{\prime \prime}$ (T.O. Plastics Inc., cat. no. 114150-1)

- Pots $15 \mathrm{~cm}$ diameter (T.O. Plastics Inc., cat. no. 127142)

- Greenhouse and/or growth chamber adjustable to $12 \mathrm{~h}$ light/8 h dark,

$25 / 28{ }^{\circ} \mathrm{C}$ equipped with cool-white lighting $\left(40-50 \mu \mathrm{mol} \mathrm{m}{ }^{-2} \mathrm{~s}^{-1}\right)$

• "Humid chamber" (see EQUIPMENT SETUP)

\begin{abstract}
- Petri dishes 100/15 (Lab SyM, cat. no. NX7171B)
- Bent glass rod in a triangular shape

- Eppendorf tubes $1.5 \mathrm{ml}$ (Axygen Scientific Inc., cat. no. MCT-150-C)

$\cdot 3 \mathrm{ml}$ syringe

- Needle $21 \mathrm{G} \times 1.25$ Prime; $(0.8 \times 32 \mathrm{~mm})$

- Water atomizer

-Zeiss LSM 510 Meta confocal microscope attached to an Axiovert $200 \mathrm{M}$ REAGENT SETUP

B\&D solution Make stock solutions of $\mathrm{A}, \mathrm{B}, \mathrm{C}$ and $\mathrm{D}$ respectively: solution $\mathrm{A}$ (2 $\left.\mathrm{M} \mathrm{CaCl}_{2}\right)$, solution $\mathrm{B}\left(1 \mathrm{M} \mathrm{KH}_{2} \mathrm{PO}_{4} \mathrm{pH} 7.0\right)$, solution $\mathrm{C}$ (20 mM Fe-citrate; this should be kept away from light), solution $\mathrm{D}\left(0.5 \mathrm{M} \mathrm{MgSO}_{4}, 0.5 \mathrm{M} \mathrm{K}_{2} \mathrm{SO}_{4}\right.$, $2 \mathrm{mM} \mathrm{MnSO}_{4}, 4 \mathrm{mM} \mathrm{H}_{3} \mathrm{BO}_{3}, 1 \mathrm{mM} \mathrm{ZnSO}_{4}, 4 \mathrm{mM} \mathrm{CuSO}_{4}, 0.2 \mathrm{mM} \mathrm{CoSO}_{4}$, $0.2 \mathrm{mM} \mathrm{Na}_{2} \mathrm{MoO}_{4}$ ). Mix $0.5 \mathrm{ml}$ per liter of each stock solution $\mathrm{A}, \mathrm{B}, \mathrm{C}$ and D. Add $8 \mathrm{ml}$ of $1 \mathrm{M} \mathrm{KNO}_{3}$ per liter, to obtain a B\&D solution supplemented with $8 \mathrm{mM}$ of nitrogen. The complete solution can be stored at room temperature (23-25 $\left.{ }^{\circ} \mathrm{C}\right)$. $\triangle$ CRITICAL To prevent contamination of B\&D solution, autoclave all stock solutions and use sterilized water; handle under sterile conditions (laminar flow cabinet).

EQUIPMENT SETUP

"Humid chamber" We use a plastic tray with transparent lid humidome: for example, Plastic tray (Acroplastics Ltd, cat. no. 113030-1); transparent lid acrodome $6^{\prime \prime} \mathrm{H} \times 21^{\prime \prime} \mathrm{L} \times 11^{\prime \prime} \mathrm{W}$ (Acroplastics Ltd, cat. no. 143850-1). The tray should be sterilized by spraying with $70 \%(\mathrm{v} / \mathrm{v})$ ethanol.
\end{abstract}

\section{PROCEDURE}

Sterilization of seeds (using ethanol/hypochlorite) $\bigcirc$ TIMING $\mathbf{3 0}$ min

1) Place around 100 seeds into a sterile $250 \mathrm{ml}$ Erlenmeyer flask and wash seeds twice with $100 \mathrm{ml}$ of sterile water. Remove water. $\triangle$ CRITICAL STEP Seeds should be sterilized to prevent contamination by fungi or other microorganisms.

\section{? TROUBLESHOOTING}

2| Add $100 \mathrm{ml}$ of $96 \%$ ethanol while gently mixing and leave for $1 \mathrm{~min}$.

\section{? TROUBLESHOOTING}

3| Discard the ethanol and rinse the seeds four times with excess sterile water.

? TROUBLESHOOTING

4| Add $100 \mathrm{ml}$ of $20 \%$ sodium hypochlorite and leave for $5 \mathrm{~min}$.

? TROUBLESHOOTING

5| Discard the sodium hypochlorite and rinse four times with excess $(200 \mathrm{ml})$ of sterile water.

? TROUBLESHOOTING

\section{Germination of bean seeds $\bigcirc$ TIMING 2 days}

6| Distribute the sterilized seeds with forceps, placing them $\sim 2 \mathrm{~cm}$ apart into a metallic tray on top of a wet sterilized paper towel.

$\triangle$ CRITICAL STEP Handle seeds in a laminar flow cabinet.

? TROUBLESHOOTING

7| Cover the tray with aluminum foil, incline the tray slightly $(\sim 2.5 \mathrm{~cm})$ and incubate in the dark for 2 days in the growth chamber at $25-28{ }^{\circ} \mathrm{C}$. All germinates should grow in the same direction owing to the inclination of the tray. Seed of a good quality should give $95-100 \%$ germination (Fig. 1a).

? TROUBLESHOOTING

8| Place the germinated seeds into wet vermiculite (B\&D) in small pots. Use one seedling per pot with autoclaved vermiculite (or alternatively into each cell of a 30- to 50-well germination tray). Leave seedlings to develop for 3 days in a growth chamber at $25-28{ }^{\circ} \mathrm{C}$ (Fig. 1b).

$\triangle$ CRITICAL STEP Water, without flooding, the tray with B\&D-supplemented solution during growth and before inoculation with Agrobacterium.

\section{Inoculum preparation ( $A$. rhizogenes K599) $\bigcirc$ TIMING 3 days}

9| $0 \mathrm{n}$ the same day that Step 8 is performed (3 days before plantlets infection, Step 11), spread 50-100 $\mu$ lof the Agrobacterium strain harboring the binary vector directly from a $-80{ }^{\circ} \mathrm{C}$ glycerol stock (LB medium containing $20 \%(\mathrm{v} / \mathrm{v}$ ) glycerol) onto LB plates with appropriate antibiotic selection. 
10| Incubate the Agrobacterium plate for 2 days at $28{ }^{\circ} \mathrm{C}$, then re-streak a single colony onto a fresh plate. Prepare a backup stock (kept at $-80^{\circ} \mathrm{C}$ ) and a working stock (also at $-80^{\circ} \mathrm{C}$ ), which are used to inoculate freshly poured plates. Working and backup stocks are obtained from fresh fully grown plates prepared as described in Step 9 by suspending the bacteria in $3 \mathrm{ml}$ of LB with $20 \%$ glycerol before freezing. By using the freshly prepared working stock glycerol, better bacterial growth and high cell density to inoculate the plants can be assured.

$\triangle$ CRITICAL STEP Do not keep the Agrobacterium strains on plates, always use an inoculum directly from a glycerol stock.

\section{? TROUBLESHOOTING}

\section{Induction of hairy roots TIMING 8 days}

11| After keeping the plants for 3 days in the growth chamber (the plants incubated in Step 8), select healthy and robust plantlets to use in the transformation experiments (Fig. 1c). $\triangle$ CRITICAL STEP Choose plants with unfolded green cotyledons, and do not use plants with developmental problems such as shorter, stunted or broken root apical meristem, because this will drastically decrease the efficiency of hairy root formation.

? TROUBLESHOOTING

12| Sterilize the glass rod by using $96 \%$ ethanol and burn it under the flame in sterile conditions.

\section{Inoculation of bacterial suspension into the cotyledonary nodes}

13| Add $1 \mathrm{ml}$ of sterile water to the Petri dish to obtain the bacterial inoculum (this will have a milky nature and be rose-colored). Collect the bacterial suspension into an Eppendorf tube (Fig. 1d).

14| Collect the suspension with the syringe and slightly wound the cotyledonary node with the needle tip, and carefully prick each plant two or three times at different positions around the node (Fig. 1e).

$\triangle$ CRITICAL STEP Make sure to repeatedly penetrate (2-3 times) the plant tissue up to the vascular tissue with the needle.

$\triangle$ CRITICAL STEP The use of $A$. rhizogenes K599 strain is very important. Other A. rhizogenes strains (e.g., A4, A15834, A8194 and A2659) are completely ineffective or induce hairy roots only in certain genotypes.

15| Inject 5-10 $\mu$ ldrops of the inoculum into the wound.

I CAUTION Handle the needles with care. In case of injury to the finger, wash the wounding site and disinfect immediately.

Autoclave used material and remaining inoculum.

$\triangle$ CRITICAL STEP Three additional controls can be performed: the first with plantlets injected with sterile water; the second with K599 strain; and the third with K599 carrying the empty binary vector. 
16 After the plantlets are infected, immediately wet the vermiculite with $\mathrm{B} \& \mathrm{D}$ supplemented with nitrogen (8 $\mathrm{mM} \mathrm{KNO}_{3}$ ). ? TROUBLESHOOTING

17| Cover the tray containing the little pots with the transparent lid acrodome sterilized with $70 \%$ ethanol. Close and seal to maintain humidity $(>90 \%$ ), which is essential for callus formation and the development of hairy roots. Callus should be observed at the wounding sites 5-7 days after infection (Fig. 1f).

$\triangle$ CRITICAL STEP To preserve plants in high-humidity levels after infection, water the plants, close the ventilation tray and seal the lid. Failure to maintain a high-humidity environment will dramatically decrease the efficiency of hairy-root formation. ? TROUBLESHOOTING

18 Keep the plants in the sealed trays for $16 \mathrm{~h}$ light $/ 8 \mathrm{~h}$ dark in a growth chamber for 8 days at $25 / 28{ }^{\circ} \mathrm{C}$. During this time, water and spray the plants with an atomizer every second day using sterile $\mathrm{B} \& \mathrm{D}$ solution containing $2-8 \mathrm{mM} \mathrm{KNO}_{3}$ as the nitrogen source, depending on further interest. Hairy roots should be approximately $3-5 \mathrm{~cm}$ in length (Fig. $\mathbf{1 g}, \mathbf{h}$ ) after this period. Plantlets injected with sterile water from neither calli nor hairy roots.

! CAUTION Use sterile B\&D solution supplemented with $2 \mathrm{mM} \mathrm{KNO}_{3}$ if hairy roots should be subsequently inoculated with Rhizobium. For other purposes, higher concentrations of nitrogen source can be used.

$\triangle$ CRITICAL STEP Temperature should not be higher than $28^{\circ} \mathrm{C}$, as higher temperatures will abort transformation. ? TROUBLESHOOTING

19| When hairy roots are fully grown from wounded sites, approximately 15 days after infection, remove the primary root by cutting the stem $2 \mathrm{~cm}$ below the hairy roots.

$\triangle$ CRITICAL STEP Frequently spray hairy roots with sterile water during main-root sectioning to prevent dehydration. ? TROUBLESHOOTING

20| Transfer plants to a new pot with wet sterile vermiculite. Place 1-3 plants into a $15 \mathrm{~cm}$ diameter pot and cover hairy roots up to $1 \mathrm{~cm}$ with sterile vermiculate. Keep plants in a growth chamber $\left(16 \mathrm{~h}\right.$ light $/ 8 \mathrm{~h}$ dark at $25-28{ }^{\circ} \mathrm{C}$; Fig. 1 ii) until hairy roots emerge.

$\triangle$ CRITICAL STEP Removal of the primary root debilitates the plant. It is essential to maintain humidity by watering with B\&D sterile solution with $2 \mathrm{mM} \mathrm{KNO}_{3}$ and cover the pot with a plastic bag with holes to decrease humidity gradually. After 5-7 days, plastic bags can be removed and plants can be transferred to a greenhouse. Water the plants everyday since hairy roots are extremely sensitive to desiccation.

? TROUBLESHOOTING

Innoculate recently emerged hairy roots $\bigcirc$ TIMING 10-12 days

21| Inoculate Rhizobium etli or R. tropici strain CIAT899 into a $250 \mathrm{ml}$ Erlenmeyer flask containing $100 \mathrm{ml}$ of PY medium supplemented with $100 \mu \mathrm{l}$ of $7 \mathrm{mM} \mathrm{CaCl}_{2}, 50 \mu \mathrm{g} \mathrm{ml}^{-1}$ rifampicin and $20 \mu \mathrm{g} \mathrm{ml}^{-1}$ nalidixic acid.

22| Incubate at $30^{\circ} \mathrm{C}$ for $24 \mathrm{~h}$ with shaking at 300 r.p.m.

23| Centrifuge for $3 \mathrm{~min}$ at 2,300g at room temperature and discard the supernatant.

24| Resuspend cells in $100 \mathrm{ml}$ of $10 \mathrm{mM} \mathrm{MgSO}_{4}$, measure $A_{600}$ of the resulting suspension and calculate the number of cells per $\mathrm{ml}$ assuming that one $A_{600}$ unit equals $5 \times 10^{8}$ cells ml-1 .

25| With a pipette, inoculate emerged hairy roots when they are $\sim 0.5-2 \mathrm{~cm}$ long with about $5-8 \times 10^{8}$ bacteria per $\mathrm{ml}$ per plant.

$\triangle$ CRITICAL STEP Only inoculate with rhizobia recently emerged hairy roots to avoid delays in nodulation and to reassume plant growth.

$\triangle$ CRITICAL STEP Hairy roots can be inoculated with rhizobia before main-root removal, although contact of inoculum with primary root should be avoided to prevent competition with hairy-root nodulation. This can be effectively done by clamping a sterile cotton plug with an antiseptic solution (i.e., $0.05 \% \mathrm{ppm}$ ) below hairy roots while inoculating.

26 Return the plants to the growth chamber $\left(16 \mathrm{~h}\right.$ light/8 $\mathrm{h}$ dark at $\left.25-28{ }^{\circ} \mathrm{C}\right)$ and stop watering for 2 days after hairy-root inoculation with Rhizobium, but keep plants in covered trays, to allow infection threads to get going. Reassume watering with sterile $B \& D$ solution with $2 \mathrm{mM} \mathrm{KNO}_{3}$ for 5 days while nodules develop.

27| Collect nodulated hairy roots to determine the phenotype and process samples for activity of reporter genes or microscopic analysis (Fig. $\mathbf{1 j}-\mathbf{l}$ ).

$\triangle$ CRITICAL STEP To facilitate the identification of transformed roots, whenever possible use $A$. rhizogenes strains with binary vectors carrying a fluorescent reporter gene (such as red fluorescent protein, green fluorescent protein (GFP) or others; see Fig. 1k). 
This is important to be considered, because we do not use a positive selectable marker and in some cultivars the efficiency of hairy roots co-transformed with a particular binary vector could vary.

\section{TIMING}

It takes 30 min to sterilize seeds, growing seedling requires 5 days, hairy root development requires 15 days and fully grown nodules in hairy roots take between 3 and 4 weeks to develop.

\section{? TROUBLESHOOTING}

Troubleshooting advice can be found in Table 1.

TABLE 1 | Troubleshooting table.

\begin{tabular}{|c|c|c|c|}
\hline Step & Problem & Possible reason & Solution \\
\hline \multirow[t]{3}{*}{$1-7$} & Poor germination & The seeds are old & Use fresh seeds \\
\hline & & The seeds were not correctly stored & Store the seeds at $4^{\circ} \mathrm{C}$ with desiccant \\
\hline & & Exceeded the time of sterilization method & $\begin{array}{l}\text { Sterilize the seeds at the indicated time and rinse with } \\
\text { excess water }\end{array}$ \\
\hline
\end{tabular}

9 and 10

Lack of hairy-roots formation

11

16 and 17

18

19

20 fungi

Formation of roots near the wounding sites

Plant desiccation
Agrobacterium culture was not fresh

Seedling were too old or not healthy

There was insufficient humidity

Contamination with

The infection took place at the distal part sterilized
Chamber or tray might be flooded, or not properly

\footnotetext{
The seedling has a developmental problem in the
primary root (i.e., stunted or was injured)
}

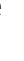

Use only plantlets with healthy well-developed root system

Use only up to 5-day-old germinated seedlings with unfolded green cotyledon

Close the tray and seal the lid, and water the plants everyday

Sterilize the tray and lid with $70 \%$ ethanol. Autoclave the pots with vermiculite and use B\&D sterile solution. Do not flood plants

Infect the plants at the cotyledonary nodes, two or three times

After the primary root was removed, plants are weak Spray or submerge in sterile water during transplant. and hairy roots tend to dehydrate rapidly
Cover plants with transparent plastic bags with holes to slowly allow plant adaptation

\section{ANTICIPATED RESULTS}

The frequency of co-transformation obtained using this procedure is high $(75-90 \%)$ when cultivars and landraces of Phaseolus spp. were infected with $A$. rhizogenes K599 containing the binary vector p35SGFPGUS+ (ref. 12). Transgenic hairy roots induced are robust, grow rapidly and are susceptible to be nodulated by inoculation with Rhizobium.

Although a positive selectable marker, such as an antibiotic or herbicide, has not been proven to be necessary (co-transformation efficiencies are in general higher than 70\%), co-transformation frequencies may vary with different binary vectors. To screen for co-transformed hairy roots, a GFP or equivalent reporter protein-expressing binary vector can be used. We are currently using a construction (pTdTRNAi) with a double tandem tomato fluorescent protein (tdT) TFP reporter gene, under the NOS promoter ${ }^{13}$ (see Fig. 1k).

In our group, we have successfully used an antisense construction (ASN30) directed against a conserved region shared by a common bean nodulin gene family encoding nodulin 30 (NPV30) (ref. 14). Interestingly, although this nodulin family is expressed in normal root nodules after the onset of nitrogen fixation ${ }^{15}$, in the downregulated nodules, the integrity of infected cells is highly impaired when antigen was detected $50 \%$ below normal protein levels, as determined by western blotting (J.-E.O. et al., unpublished observations, data not shown). Another example that was tested in the bean hairy root 
PROTOCOL

system was the subcellular localization of NPV30 by expressing its signal peptide (PSN30) fused to a GFP- $\beta$-glucuronidase (GFP5-gusA) cloned into the pCAMBIA 1304 (pCAMBIA-PSN30GFP-GUS) vector. We analyzed bean root-nodule sections by confocal microscopy. In Figure 1l, it can be observed that this hydrophobic signal peptide directs the GFP-GUS fusion protein to the membranes that surround rhizobia-infected cells, forming intercellular aggregates or patches (Fig. 1l, white arrows); it is also confined to the cytoplasm of uninfected and epidermal cells.

We are currently testing antisense and RNAi constructs to downregulate, at the translational and mRNA silencing level, several receptor-like kinases and key signaling proteins, involved in perception of $R$. etli, and in nodule development and metabolism.

ACKNOWLEDGMENTS This research was partially supported by CONACYT 42562-0 and by Dirección General de Asuntos del Personal Académico IN-215805-2 grants. We thank Dr. José Luis Reyes and Oswaldo Valdés L. for pTdTRNAi vector construction and Olivia Santana for technical assistance.

COMPETING INTERESTS STATEMENT The authors declare no competing financial interests.

Published online at http://www.natureprotocols.com

Reprints and permissions information is available online at http://npg.nature.com/ reprintsandpermissions

1. McClean, P., Kami, K. \& Gepts, P. Genomic and genetic diversity in common bean. in Legume Crop Genomics (eds. Wilson, R.F., Stalker, H.T. \& Brummer, E.C.) 60-82 (AOC Press, Champaign, IL, 2004).

2. Broughton, W.J. et al. Beans (Phaseolus spp.) model food legumes. Plant Soil 252, 55-128 (2003).

3. Christou, P. Biotechnology applied to grain legumes. Field Crops Res. 53, 83-97 (1997).

4. Aragão, F.J.L., Vianna, G.R., Albino, M.M.C. \& Rech, E.L. Transgenic dry bean tolerant to the herbicide glufosinate ammonium. Crop Sci. 42, 1298-1302 (2002).

5. Gepts, P. et al. Genomics of Phaseolus beans, a major source of dietary protein and micronutrients in the tropics. in Genomics of Tropical Crop Plants (eds. Moore, P.H. \& Ming, R.) (Springer, Berlin, 2007) (in press).

6. Zhang, Z., Coyne, D.P. \& Mitra, A. Factors affecting Agrobacterium-mediated transformation of common bean. J. Am. Soc. Hortic. Sci. 122, 300-305 (1997).
7. Veltcheva, M., Svetleva, D., Petkova, S. \& Perl, A. In vitro regeneration and genetic transformation of common bean (Phaseolus vulgaris L.) problems and progress. Sci. Hortic. 107, 2-10 (2005).

8. Liu, Z., Park, B.J., Kanno, A. \& Kameya, T. The novel use of a combination of sonication and vacuum infiltration in Agrobacterium-mediated transformation of kidney bean (Phaseolus vulgaris L.) with lea gene. Mol. Breed. 16, 189-197 (2005).

9. Brasileiro, A.C.M. et al. Suceptibility of common and tepary beans to Agrobacterium spp. Strains and improvement of Agrobacterium-mediated transformation using microprojectile bombardment. J. Am. Soc. Hortic. Sci. 121, 810-815 (1996).

10. Zambre, M. et al. A reproductible genetic transformation system for cultivated Phaseolus acutifolius (tepary bean) and its use to asses the role of arcelins in resistence to the Mexican bean weevil. Theor. Appl. Genet. 110, 914-924 (2005).

11. Oldroyd, G., Harrison, M. \& Udvardi, M. Peace talks and trade deals: keys to long-term harmony in legume-microbe symbioses. Plant Physiol. 137, 1205-1210 (2005).

12. Estrada-Navarrete, G. et al. Agrobacterium rhizogenes-transformation of the Phaseolus spp.: a tool for functional genomics. Mol. Plant Microbe Interact. 19, 1385-1393 (2006).

13. Shaner, N.C. et al. Improved monomeric red, orange and yellow fluorescent proteins derived from Discosoma sp. red fluorescent protein. Nat. Biotechnol. 12, 1567-1572 (2004).

14. Ramírez, M. et al. Sequencing and analysis of common bean ESTs: building a foundation for functional genomics. Plant Physiol. 137, 1211-1227 (2005).

15. Campos, F. et al. Characterization and gene expression of nodulin Npv30 from Common bean. Plant Physiol. 109, 363-370 (1995). 